\title{
The Chesapeake Bay Interpretive Buoy System
}

\author{
Doug Wilson \\ NOAA Chesapeake Bay Office \\ 410 Severn Avenue, Suite 107A \\ Annapolis, MD 21403
}

\begin{abstract}
The Chesapeake Bay Interpretive Buoy System (CBIBS) is an innovative system to collect, transmit and interpret real-time environmental data from the Chesapeake Bay to a wide variety of constituents - including scientists, on-the-water users, educators, and natural resource decision-makers - and to fill critical observational gaps in the Chesapeake Bay. CBIBS is a component of the Chesapeake Bay Observing System (CBOS) and the US Integrated Ocean Observing System (IOOS), addressing IOOS goals in the Chesapeake Bay region. The CBIBS platforms provide critical real-time data on environmental conditions and water quality, and the supporting data management and delivery systems system deliver products and interpretive information of interest to the targeted user segments utilizing multiple media methods. Primary interfaces are though the web site $W W W . B U O Y B A Y$.ORG and via an extensive data and information voice application at 877-BUOYBAY. The System delivers high quality educational content based on real-time and archived data and expands the delivery of meaningful watershed educational experiences to promote environmental stewardship of Chesapeake Bay. The System is also an integral interpretive component of the National Park Service's Captain John Smith Chesapeake National Historic Trail. CBIBS buoys are presently deployed at six locations on the Chesapeake Bay: Near the mouths of the Potomac, Patapsco, Rappahannock, and Susquehanna Rivers; and in the James and Elizabeth Rivers. CBIBS platforms are AXYS Watchkeeper buoys with standard sensors including meteorological (wind speed and direction, air temperature, relative humidity, barometric pressure); water quality (WETLabs WQM measuring temperature, conductivity, pressure, dissolved oxygen, turbidity, and chlorophyll A); current profiles (Nortek Aquadopp Profilers); and waves (TRIAXYS wave sensors). Some platforms are also measuring nitrates (Satlantic ISUS) and GPS-derived water level. Real time data are reported at 10 minute to 1 hour intervals, depending on the parameter, via EVDO wireless Broadband static IP modems. The interpretive nature of the buoys, their use of multiple media (phone, web, mobile devices) to deliver data, and the educational curricula that are being built around them, are unique to this system. Support for operational oceanographic measurements from a broad and diverse user base is a critical asset to maintaining long term sustainability and funding for a system.
\end{abstract}

\section{BACKGROUND}

The Chesapeake Bay Interpretive Buoy System (CBIBS) was conceived as a multipurpose enterprise to meet the needs of regional users for products and information necessary for the understanding, protection, restoration, and management of the Chesapeake Bay. Specifically, the design of the system addresses the intersecting needs of three significant user groups important to the Chesapeake Bay:

Groups engaged in marine activities, with a special mission to support the National Park Service's Captain John Smith Chesapeake National Historic Trail. Present buoys are located at historically significant locations along the Trail, and the System supports educational and informational tools to interpret the Captain John Smith Chesapeake National Historic Trail;

Environmental and natural resource planners and decision makers, and the scientists, analysts, and applications developers who support them. CBIBS employs integrated ocean observing system methods and technology to meet the needs of Chesapeake Bay users. CBIBS is a component of the U.S. Integrated Ocean Observing System, supported by the NOAA Chesapeake Bay Office (NCBO) and Chesapeake Bay Observing System (CBOS) partners. CBIBS provides an unparalleled opportunity to demonstrate the broad utility of observing systems.

Education and Outreach interests. Recognizing that efficient use of environmental information requires an environmentally literate audience, a major focus of CBIBS is developing educational and interpretive context for the information provided by the observing system. Users include educators and their students, and environmental, historical, geographical, and cultural interpreters and their interest base.

The CBIB System consists of real-time reporting data collection platforms, a shoreside data acquisition and management system, and suite of web-based and other media applications that utilize, deliver, and interpret the data for targeted users. Data management and application development services have been developed by Tellus Applied Sciences of Williamsburg, VA. Data and content are available to the public for further application development; present partners using the data include the Chesapeake Bay Foundation, NOAA's National 
Estuarine Reserves System, the National Weather Service, the Sultana Project, the Chesapeake Bay Observing System, Weatherflow, the National Geographic Society, and Nauticus Maritime Museum of Norfolk.

The rationale for CBIBS placement and expansion balance the needs of the three primary user communities supported by the system. Mooring locations through 2008 are shown in Table 1 and Fig. 1. The Nauticus buoy represents a cost-sharing partnership between CBIBS and the Nauticus Maritime Museum in Norfolk, VA. Expansion of the system is expected in 2009.

TABLE 1

General Information on present CBIBS platforms

\begin{tabular}{|l|c|l|l|c|l|}
\hline Name & $\begin{array}{c}\text { USCG } \\
\text { Designation }\end{array}$ & Latitude & Longitude & Depth (m) & Deployed \\
\hline Jamestown (James R) & J & $37.2044 \mathrm{~N}$ & $76.7774 \mathrm{~W}$ & 13 & $5 / 07$ \\
\hline Point Lookout (Potomac R) & PL & $38.0330 \mathrm{~N}$ & $76.3356 \mathrm{~W}$ & 13 & $7 / 07$ \\
\hline Patapsco (Baltimore Approach) & SN & $39.1519 \mathrm{~N}$ & $76.3913 \mathrm{~W}$ & 7 & $8 / 07$ \\
\hline Stingray Point (Rappahannock R) & SR & $37.5674 \mathrm{~N}$ & $76.2572 \mathrm{~W}$ & 7 & $7 / 08$ \\
\hline Susquehanna (Havre de Grace) & SH & $36.8460 \mathrm{~N}$ & $76.3025 \mathrm{~W}$ & 12 & $9 / 08$ \\
\hline Nauticus (Elizabeth R) & $\mathrm{N}$ & $39.5444 \mathrm{~N}$ & $76.0766 \mathrm{~W}$ & 7 & $9 / 08$ \\
\hline
\end{tabular}

\section{SYSTEM SPECIFICATIONS}

Platforms

The six existing CBIBS platforms are moored buoys. Initial design requirements included the following criteria: deployable in 5-50 m water depths in the Chesapeake Bay, its tributaries and nearby coastal waters; with recommended mooring hardware capable of withstanding $45 \mathrm{~m} / \mathrm{s}$ winds, $3 \mathrm{~m}$ seas, and $1.5 \mathrm{~m} / \mathrm{s}$ currents; lightweight $(<600 \mathrm{~kg})$; serviceable and towable by small boat; in-situ sensors removable from above the surface. The AXYS $1.75 \mathrm{~m}$ diameter Watchkeeper Buoy (WKB) has been selected competitively for each deployment. In addition to meeting the functional requirements, the WKB has a distinctive 'look and feel' that makes it immediately identifiable to the public (Fig. 2), including consistent signage with Coast Guard designation and association with the Captain John Smith National Historic Trail (Fig. $\mathrm{X}$ ). Mooring depths of existing platforms range from 7 to 13 meters. Anchors are stacks of three steel railroad wheels with a total weight of around $1000 \mathrm{~kg}$, with enough 1" mooring chain for a 2.5:1 scope connected to a $2 \mathrm{~m}$ chain bridle with a swivel. Power is supplied by 4 GNB SunLyte 5000X 12 volt, $100 \mathrm{amp} \mathrm{hr}$ batteries charged by $4 \times 20 \mathrm{~W}$ solar panels. Primary communications are carried out via CDMA EVDO modem on the Verizon Wireless broadband network. A Skywave Inmarsat D+ terminal provides GPS positioning and optional communications and tracking should a break free and leave cellular coverage. Navigation lights are Carmanah Amber 601 programmed to flash once per 4 seconds.

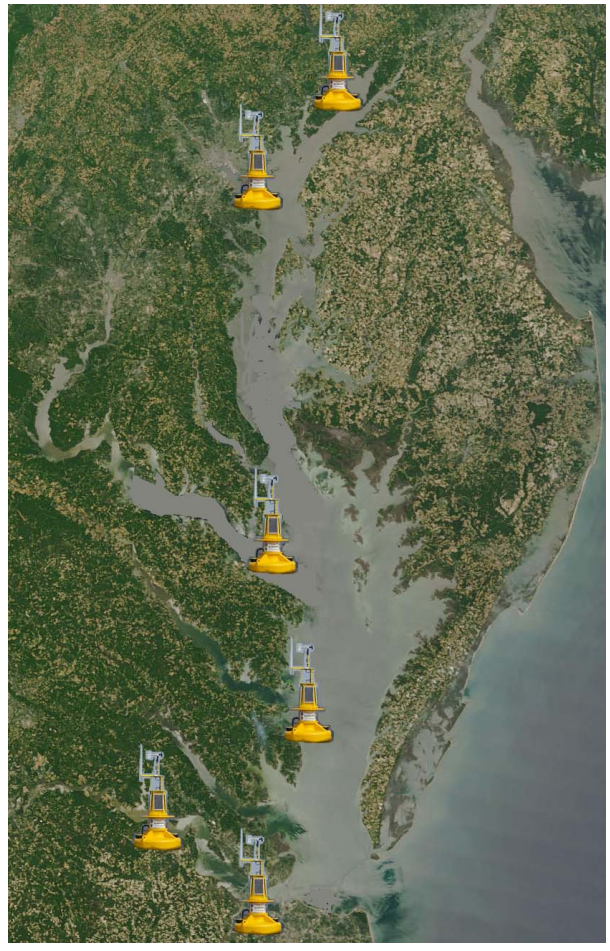

Fig. 1. Graphical depiction of present CBIBS platform locations

Sensors

All CBIBS buoys presently have the following sensors and sampling frequencies::

- Meteorological package consisting of an R.M. Young 05103 anemometer, a Rotronics temperature / relative humidity sensor, and a Vaisala barometric pressure sensor. Buoy orientation for true wind is provided by a KVHC100 compass. (10 min)

- Current profiles using a Nortek Aquadopp $1 \mathrm{mHz}$ profiler. (60 min).

- Water quality parameters (temperature, conductivity, pressure, dissolved oxygen, turbidity, and chlorophyll A) using a WETLabs WQM. (60 min)

The current profiler and WQM are mounted on racks in separate $25 \mathrm{~cm}$ PVC through-hull wells on the WKB at a depth of approximately $0.5 \mathrm{~m}$, removable for servicing from the surface. 

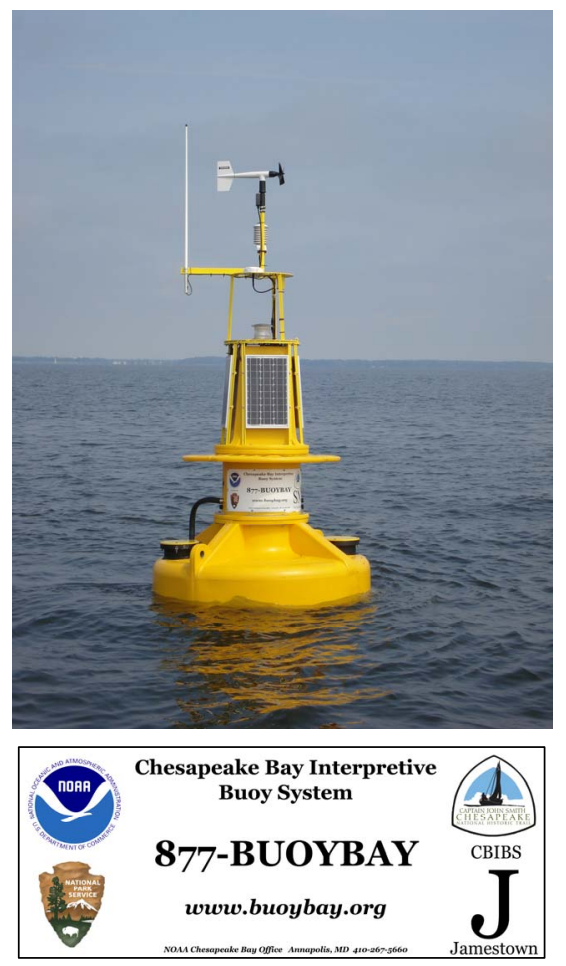

Fig. 2. Patapsco CBIBS buoy on station; Standard CBIBS buoy signage.

Four of the CBIBS buoys - including all those located in the open Chesapeake Bay - have internally mounted AXYS TRIAXYS OEM Wave Sensors. (60 min)

Two new sensors will be integrated into individual buoys in 2008. A Satlantic ISUS Nitrate Monitor will be mounted in a CBIBS buoy located at the mount of the Susquehanna River, the major nutrient source for Chesapeake Bay. Another buoy will host a cooperative project with the NOAA National Geodetic Service to measure water level using a buoy-mounted GPS sensor. The buoys have the DCP and power capacity for additional sensors; a test deployment of phosphate sensors is planned for 2009.

\section{Performance}

A major problem with moored water quality measurements is bio-fouling. The WETLabs WQM has a pumped pathway for temperature, conductivity, and dissolved oxygen water flow, with a chlorine bleach injection system Following each $10 \mathrm{~min} /$ hour average, a dilute bleach solution is pumped through the system. Optical sensors for chlorophyll-A and turbidity are kept clean by a copper wiper, and Temperature and Conductivity sensors are enclosed in copper cylinders. While CBIBS is only now conducting a careful analysis of sensor performance via a regular sampling program, it appears that these sensors only require removal for external cleaning, rinsing, and bleach replenishment at no less than three month intervals even in summer, with annual refurbishment and recalibration. These results are consistent with those reported for the instrument in an Alliance for Coastal Technologies test [1]. Aquadopp sensors are painted with antifouling and need cleaning at similar intervals. The buoys themselves are typically detached at the bridle by a diver and towed to shore (usually a local marina) where they can be quickly hauled using a crane or travel lift, pressure cleaned, repaired if needed, and returned to the buoyed chain. Buoys in the northern Chesapeake Bay may need to be removed for ice during extreme winters (this was not a problem in 2007-2008).

Validation testing has been performed on the CBIBS buoy mounted current and wave sensors through comparison with a co-located bottom mounted Nortek AWAC. Detailed results are reported elsewhere in these Proceedings. To summarize, for all currents greater than $0.1 \mathrm{~m} / \mathrm{s}$, the mean of the absolute value of the difference in current magnitude was less than $0.01 \mathrm{~m} / \mathrm{s}$. The mean of the absolute value of difference in current direction was $5^{\circ}$. Wave studies are continuing, but preliminary results indicate that the heavy buoy damps the predominantly short, low-amplitude Chesapeake Bay waves, underestimating maximum wave height by about $50 \%$ - however that factor appears to be consistent enough to allow a linear correction.

\section{Data Transmission and Management}

Onboard data acquisition and control are handled by an AXYS Watchman 500 data collection platform (2 modules). AXYS DMS software (running on a commercial 'virtual' server system) downloads data to an SQL data base. XML-based Web Services connect this data 'back end' to data management 'middleware'. Within the middleware, a Data Archive Handler performs any necessary transformations and preliminary QA/QC checks on incoming data before storing the data and appropriate metadata. A Data Retrieval Handler interfaces with Storage and provides external and internal access to the data. It contains an OpenDAP server, access to external data sources, and a Client Data Request Handler. Requests include browser based or designated users (for example, the Verizon voice IVR or supported external applications like kiosks) via an API key. For internal management, applications can provide notification for off-line buoys, erroneous sensors, or deviations from a geographic location ('anchor watch').

\section{ASSOCIATED APPLICATIONS}

III.

The primary web site for CBIBS is $\boldsymbol{W W W . B U O Y B A Y . O R G}$. The site addresses the three user groups with sections devoted to: 


\section{Explore Buoy Data and Access Data and Metadata}

These pages serve the needs of the traditional observing system users. They include a Google Maps-based buoy locator page; a page displaying all the most recent data readings; a comprehensive graphing tool to visualize data time series; and a page to download single sensor or integrated data sets.

\section{Visit the Buoys}

These pages provide access to real time data for those on the water or considering a trip, and also deliver historical, geographical, and environmental information tied to the buoy locations. In addition to basic data products, there is an option for data delivery via mobile device, and access to informational audio tracks. These tracks, as well as audio data access, are also available via the 877-BUOYBAY phone service.

\section{Buoys in the Classroom}

This section contains both INVESTIGATIONS and CURRICULUM sections. Investigations are modules that explain environmental concepts to the user using real-time data; presently there are modules explaining temperature and turbidity. The curriculum sections have extensive modules - ESTUARIES 101 and CHESAPEAKE 102 - developed by teachers and education professionals to utilize real-time data in classrooms. The NOAA Chesapeake Bay Office (chesapeakebay.noaa.gov) offers teacher training in the use of these modules, as well as grants through the B-WET program to develop other teaching applications.

The system also supports applications for data delivery through RSS feeds and widgets, or any XML requests. A free-standing kiosk is being designed - duplicating the look of the buoy and featuring a touchscreen interface - and will be implemented on shore in view of the Nauticus buoy on the Elizabeth River in Virginia.

\section{FUTURE EXPANSION AND SUMMARY}

There are plans for system expansion by two or three buoys in 2009 from the base CBIBS budget, if available. In addition, discussions are underway with partners for new cooperative deployments. There is also potential to develop an interpretive component for other existing observing platforms. The interpretive nature of the buoys, their use of multiple media (phone, web, mobile devices) to deliver data, and the educational curricula that are being built around them, are unique to this system. Support for operational oceanographic measurements from a broad and diverse user base is a critical asset to maintaining long term sustainability and funding for a system.

\section{REFERENCES}

[1] Janzen, C, N. Larsen, and C. Moore, WQM: New Instrumentation for Coastal Monitoring, Sea Technology, Feb 2008.

[2] Wilson, D and E. Siegel, Evaluation of Current and Wave Measurements from a Coastal Buoy, Proceedings, OCEANS '08, 2008. 